\title{
Metabolic Responses to Protein Restriction During Pregnancy in Rat and Translation Initiation Factors in the Mother and Fetus
}

\author{
PRABHU S. PARIMI, CHANTAL CRIPE-MAMIE, AND SATISH C. KALHAN \\ Schwartz Center for Metabolism and Nutrition, Department of Pediatrics, Case Western Reserve \\ University at MetroHealth Medical Center, Cleveland, Ohio, 44109, U.S.A.
}

\begin{abstract}
ABST
A low-protein diet during pregnancy in the rat results in
intrauterine growth restricted (IUGR) fetuses. The adaptive re-
sponses of the mother to low-protein diet and the mechanisms of
IUGR in this model are not understood. In the present study, we
report the maternal metabolic responses to protein restriction and
their impact on growth, carcass composition, and translation
initiation in the fetus. Pregnant Sprague-Dawley rats were pair-
fed either a $6 \%$ protein (LP, $n=7)$ or a $24 \%$ protein $(\mathrm{NP}, n=$
7) diet from conception until delivery. Plasma amino acids and
urea levels and rate of oxygen consumption were measured
sequentially through pregnancy. Translation initiation factors
eIF2 $\alpha$, Ser ${ }^{51}$ phosphorylated eIF2 $\alpha$, eIF4E, phosphorylated
eIF4E, and $4 \mathrm{E}-\mathrm{BP} 1$ were quantified in the maternal and fetal
muscle and liver. Protein restriction resulted in higher rate of
oxygen consumption ( $p<0.01)$, lower plasma branched chain
amino acid $(p<0.05)$ in the mother, and lower plasma histidine
levels $(p<0.05)$ in the fetus. Plasma urea nitrogen was lower in
the LP group throughout gestation. The phosphorylated $4 \mathrm{E}-\mathrm{BP} 1$
\end{abstract}
ABSTRACT

( $\gamma$ form) in the maternal liver was 4-fold higher in the LP group. The phosphorylated eIF $2 \alpha$ was higher in the livers of IUGR fetuses. We speculate that the lower plasma branched chain amino acids in the mother during early pregnancy may be due to a lower rate of protein turnover in the LP group. The mechanism of increased energy consumption due to protein restriction remains unclear. The data on translation initiation factors suggest a higher rate of protein synthesis in the maternal liver and a lower rate in the fetal liver in response to protein restriction. (Pediatr Res 56: 423-431, 2004)

LP, low protein
NP, normal protein
OPA, ophthaldialdehyde
eIF, eukaryotic initiation factor
4E-BP1, 4E binding protein 1
$\dot{\mathbf{V}}_{\mathbf{O}_{\mathbf{2}}}$, rate of oxygen consumption

LP, low protein

OPA, ophthaldialdehyde

eIF, eukaryotic initiation factor

$\dot{\mathrm{V}}_{\mathbf{2}}$, rate of oxygen consumption
Epidemiologic studies in humans have shown a significant correlation between intrauterine growth restriction (IUGR), low birth weight, and a number of morbidities in adult life (1-3). A number of studies in animals, particularly rat, have confirmed these findings (4-7). Protein restriction during pregnancy in the rat has often been used to induce IUGR in the fetus. In the present study we have examined the adaptive responses of the mother to protein restriction during pregnancy. Specifically, we have examined the temporal changes in plasma amino acid and urea concentration, and changes in oxygen consumption in the mother.

Adaptive responses to normal pregnancy in humans and animals are characterized by hypoaminoacidemia, a lower rate of urea synthesis, and a lower rate of protein turnover as

Received September 9, 2003; accepted April 23, 2004.

Correspondence: Prabhu S Parimi, M.D., Schwartz Center for Metabolism and Nutrition, 2500 MetroHealth Dr., Room G-735, Cleveland, OH 44109-1998, U.S.A.; e-mail: pparimi@metrohealth.org

Supported by grant HD11089 from the National Institutes of Health and institutional support from MetroHealth Medical Center, Cleveland, $\mathrm{OH}$.

DOI: 10.1203/01.PDR.0000136277.10365.84 compared with nonpregnant controls $(8,9)$. Studies in rat have shown an increase in fractional rate of protein synthesis in the liver during pregnancy. No significant effect of pregnancy on protein synthesis in skeletal muscle was observed in this study (10). Dietary restriction of protein to $9 \%$ in pregnant rat results in specific changes in plasma amino acid concentration, i.e. an increase in glycine and glutamine concentration, and a decrease in branched chain amino acids and threonine concentration (11). However, these studies were not controlled for energy intake, since a low-protein diet, less than $9 \%$ protein, also caused a decrease in food intake in both pregnant and nonpregnant rats $(11,12)$.

Low protein intake in nonpregnant rats is associated with a higher rate of energy expenditure (13-16). Whether protein restriction during pregnancy elicits a similar increase in energy expenditure has not been examined. In the present study, an isocaloric (pair-fed) control group was also studied to examine the effect of isocaloric low-protein diet on maternal metabolism.

Translation initiation and peptide chain elongation and termination constitute the three steps involved in protein synthe- 
sis. The initiation of mRNA translation involves a number of proteins (eIF). Two intermediary steps in the initiation pathway are subject to regulation in vivo: generation of eIF2.GTP and phosphorylation of 4E-BP1 (17). Phosphorylation of eIF2 $\alpha$ sequesters eIF2B, a guanidine-nucleotide exchange factor mediating the formation of eIF2.GTP, resulting in inhibition of the first step in translation initiation. In addition, alterations in the intracellular insulin-signaling pathway inhibit phosphorylation of 4E-BP1 and prevent the release of eIF4E, resulting in inhibition of Cap-dependent mRNA translation. These regulatory steps are modulated by alterations in the levels of amino acids, growth factors, and insulin (18-22). We hypothesized that protein restriction, by reducing plasma amino acid concentration in the mother, will decrease the availability of amino/nitrogen to the fetus and will restrict fetal growth by inhibiting the initiation of mRNA translation.

\section{METHODS}

All studies were performed in the animal care facility at Case Western Reserve University, MetroHealth Medical Center, Cleveland, $\mathrm{OH}$. Animal handling and procedures were reviewed and approved by the Institutional Animal Care and Use Committee and conformed to American Association for Accreditation of Laboratory Animal Care Guidelines.

Pregnant Sprague-Dawley rats were purchased from ZivicMiller Laboratories (Zelienople, PA, U.S.A.). The animals were housed under constant conditions of temperature (22 \pm $1^{\circ} \mathrm{C}$ ) and light (on at $0600 \mathrm{~h}$, off at $1800 \mathrm{~h}$ ), with free access to water. The experimental group (LP, $n=7$ ) was placed on a $6 \%$ protein diet from $\mathrm{d} 1$ of gestation until delivery. The control group (NP, $n=7$ ) was pair-fed using a $24 \%$ protein diet. The pair feeding was performed by offering the amount of food taken by the experimental animal pair (LP) on the previous day to the NP group. The composition of the diets is displayed in Table 1 [24\% protein (TD90017), 6\% protein (TD90016); Harlan Teklad, Madison, WI, U.S.A.]. The protein source of the diets was casein. The diets were similar in metabolizable

Table 1. Composition of diets (\% by wt)

\begin{tabular}{lcc}
\hline & NP & LP \\
& $(24 \%$ protein $)$ & $(6 \%$ protein $)$ \\
\hline Protein (casein) & 24.02 & 6.00 \\
Carbohydrate & 57.60 & 75.60 \\
Fat & 5.48 & 5.48 \\
Choline & 1.43 & 1.43 \\
Mineral mix & 1.33 & 1.33 \\
Vitamin mix & 1.00 & 1.00 \\
Linoleic acid & 2.96 & 3.07 \\
Metabolizable energy* (kcal/g) & 3.76 & 3.76 \\
Amino acids & & \\
Leucine & 2.21 & 0.55 \\
Isoleucine & 1.38 & 0.35 \\
Valine & 1.66 & 0.41 \\
Phenylalanine and tyrosine & 2.48 & 0.62 \\
Lysine & 1.93 & 0.48 \\
Threonine & 1.05 & 0.26 \\
Histidine & 0.69 & 0.17 \\
Arginine & 0.91 & 0.23 \\
\hline
\end{tabular}

* Metabolizable energy of the diets was determined by the manufacturer using the Atwater method. energy and in the content of fat and linoleic acid. The diets contained a similar amounts of choline, mineral mix, and vitamin mix. The carbohydrate content in the LP diet was increased to make the diet isoenergetic. The carbohydrates in the NP and LP diet consisted of cornstarch and sucrose. The diets did not differ in the amount of cornstarch (20\%), however, the LP diet had a higher amount of sucrose $(57 \%)$ when compared with NP diet (39\%). The remainder of the carbohydrates in the diet was composed of fiber and cellulose.

The amount of food and water intake was measured daily. The animals were weighed every $3 \mathrm{~d}$ during the experimental period (d 1 to $d 21$ of gestation).

Blood samples from the pregnant rats were obtained between 0900 and $1000 \mathrm{~h}$ from the tail on $\mathrm{d} 10,15$, and 18 of gestation, and by cardiac puncture on the day of delivery. The animals were not fasted before blood sampling. On d 21 of pregnancy, following pentobarbital anesthesia, laparotomy was performed, pups were exteriorized, and blood samples obtained by making an incision in the axilla, while the pups were still attached to the placenta. The pups were rapidly delivered, killed by decapitation, and the tissues harvested. The fetal liver, heart, and brain were weighed and rapidly frozen in liquid nitrogen. The placentae were washed in cold normal saline, blotted dry, weighed, and frozen in liquid nitrogen. Maternal liver and skeletal muscle were quickly frozen in liquid nitrogen for later analysis.

\section{Oxygen Consumption}

The rate of oxygen consumption $\left(\dot{\mathrm{V}}_{2}\right)$ in the $\mathrm{NP}(n=5)$ and the LP $(n=5)$ groups was determined by indirect respiratory calorimetry using Deltatrac II metabolic monitor (SensorMedics Corp., Yorba Linda, CA, U.S.A.). The metabolic monitor was calibrated daily before each measurement. The measurements were obtained on d 15, 18, and 20 of gestation between 0900 and $1000 \mathrm{~h}$. The animals (in their cages) were placed under a Plexiglas chamber and allowed to acclimatize for 30 min. The rate of oxygen consumption and carbon dioxide production was measured for $60 \mathrm{~min}$.

\section{Analytical Methods}

Plasma concentration of glucose was determined by glucoseoxidase method and the urea levels by urease method using a Beckman analyzer (Beckman Coulter, Fullerton, CA, U.S.A.). The plasma levels of lactate were measured using a 2300 STAT glucose-lactate analyzer (YSI Inc., Yellow Springs, OH, U.S.A.). Triglyceride levels in the plasma were quantitated enzymatically using a commercial kit (Sigma Chemical Co., St. Louis, MO, U.S.A.). The concentration of amino acids in the maternal and fetal plasma was measured by HPLC equipped with a fluorescent detector using the OPA derivative and precolumn derivatization (23).

\section{Carcass Analysis}

The carcass analysis of the fetuses (LP, $n=19$; NP, $n=16$ ) was performed according to method of Leshner et al. (24). The eviscerated carcasses were dried to a constant weight in an oven at $60^{\circ} \mathrm{C}$. The water content was calculated as the differ- 
ence between the original (wet) weight and the dried weight of the carcass. Subsequently, the dried carcass was pulverized to a fine powder and the fat content was determined by ether extraction. The protein content of the remaining fat-free material was measured by the Biuret method, using BSA as standard. The data were expressed as a percentage of the original wet weight.

\section{Western Blot Analysis}

Antibodies to eIF $2 \alpha$ and eIF4E were purchased from Santa Cruz Biotechnology (Santa Cruz, CA, U.S.A.). $\mathrm{Ser}^{51}$ eIF2 $\alpha$, P-eIF4E $\left(\mathrm{Ser}^{209}\right)$, and P-4EBP-1 (Thr $\left.{ }^{37 / 46}\right)$ were purchased from Cell Signaling Technology (Beverly, MA, U.S.A.).

Isolation of protein. Preweighed liver and muscle tissues were homogenized in ice-cold homogenizing buffer consisting of (mM) 20 Tris, pH 7.6; 0.1 EDTA; 0.5 EGTA; 0.1\% triton-X; 250 sucrose; and $50 \mu \mathrm{L} / 5 \mathrm{~mL}$ protease inhibitor mixture. The resulting homogenates were centrifuged at $10,000 \mathrm{~g}$ for $30 \mathrm{~min}$ at $4^{\circ} \mathrm{C}$ to separate cellular debris, mitochondria, nuclei, and plasma membranes. The supernatant containing cytosolic and particulate fraction was again centrifuged at $20,000 \mathrm{~g}$ for 30 min at $4^{\circ} \mathrm{C}$, and the particulate fraction was removed for analysis. The homogenizing buffer was modified for the determination of the phosphorylated forms of eukaryotic initiation factors as follows. Sucrose was excluded from the buffer and the following were added $(\mathrm{mM}): 150$ sodium chloride, 2.5 sodium pyrophosphate, $1 \beta$-glycerophosphate, and 1 sodium vanadate. The homogenate was centrifuged at $10,000 \mathrm{~g}$ for 10 min and the supernatant was removed for analysis. Concentration of the protein in the respective fractions was determined using the Bio-Rad protein assay kit (Bio-Rad, Hercules, CA, U.S.A.). BSA was used as the standard.

Electrophoresis and immunoblot analysis. Protein $(30 \mu \mathrm{g})$ was diluted in $2 \times$ buffer containing $(\mathrm{mM}) 100$ Tris $\mathrm{HCl}, \mathrm{pH}$ $6.8 ; 20 \% \beta$-mercaptoethanol; $4 \%$ SDS; $0.2 \%$ bromophenol blue; and $20 \%$ glycerol. The proteins were separated by a $12.5 \%$ SDS-PAGE and were electrophoretically transferred to Immobilon-P polyvinylene difluoride membranes (Bio-Rad). Membranes were subjected to Ponceau stain to verify equal loading of the proteins.

After a brief wash in methanol and removal of residual methanol by washing in distilled water and TBS, the mem- branes were incubated in a blocking buffer containing 5\% nonfat dry milk in $(\mathrm{mM}) 10$ Tris, $\mathrm{pH} 7.4 ; 150 \mathrm{NaCl}$; and $0.1 \%$ Tween-20 (TBS-T) for $1 \mathrm{~h}$ at room temperature. They were then incubated with primary antibody diluted in blocking buffer for $1 \mathrm{~h}$ as follows: eIF2 $\alpha$ (1:500), eIF4E (1:500). Incubation with primary antibodies, used to detect phosphorylated proteins, were performed at $4{ }^{\circ} \mathrm{C}$ overnight as follows: $\mathrm{Ser}^{51}$ eIF2 $\alpha$ P (1:500), P-4EBP-1 (1:500), and P-eIF4E (1:1000). After incubation at either room temperature or at $4^{\circ} \mathrm{C}$, the membranes were washed once for $15 \mathrm{~min}$ and three times for $5 \mathrm{~min}$ each in TBS-T. Subsequently, they were incubated with secondary antibody diluted in blocking buffer for $1 \mathrm{~h}$ as follows: horse radish peroxidase (HRP)-conjugated anti-rabbit IgG (1:5000) for phosphorylated antibodies, and HRP-conjugated donkey anti-goat IgG (1:5000) for eIF $2 \alpha$ and eIF4E antibodies. The membranes were washed thrice for 5 min each in TBS-T and a final wash was performed with TBS without Tween-20 for $5 \mathrm{~min}$. Immunoreactive proteins were detected using the SuperSignal Chemiluminescent Substrate kit (Pierce Chemical, Rockford, IL, U.S.A.) after exposure to a Kodak film for 1-5 min. The density of the immunoreactive proteins was quantitated using scanning densitometry (GS-710, Imaging Densitometer; Bio-Rad)

Each individual membrane was first reacted with eIF2 $\alpha$, stripped as described by the manufacturer (Pierce Chemical), and reacted again with eIF4E antibody. A similar procedure was followed for detection of phosphorylated proteins. Proteins from the NP and LP pups from each animal were run simultaneously on one membrane. The proteins from the maternal liver and muscle of the NP and LP group were also resolved simultaneously on a single membrane.

\section{Statistical Analysis}

Values presented are mean \pm SEM. Statistical evaluation of the data were performed by ANOVA to test for overall differences between the LP and NP groups. In addition, one-way repeated measures of ANOVA were performed to determine differences in oxygen consumption, plasma urea, and plasma amino acids at various points in gestation. The data of the translation initiation factors on $\mathrm{d} 21$ of gestation in the NP and LP groups was compared using ANOVA as well as $t$ test to
Food consumption

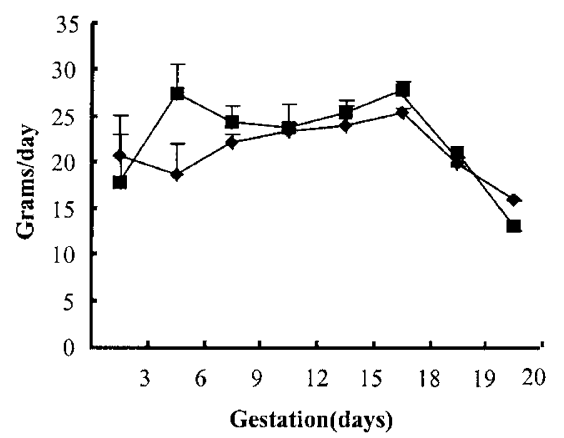

Protein

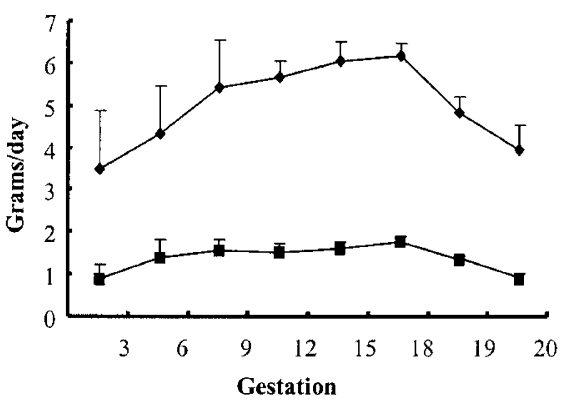

Maternal weight

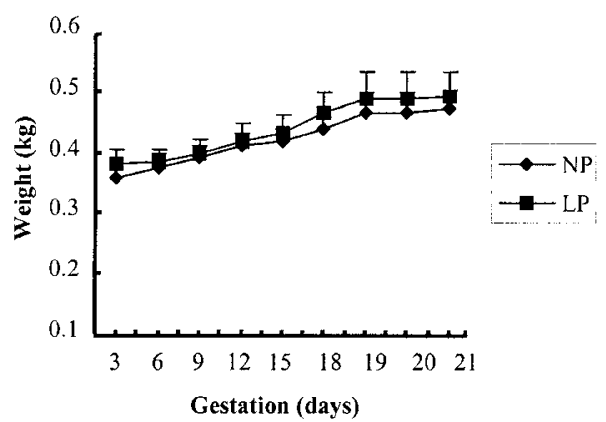

Figure 1. Food intake, protein intake, and weight of mothers fed $6 \%$ protein diet (LP, $n=7)$ and $24 \%$ protein diet (NP, $n=7)$ throughout pregnancy. Solid square, LP; solid diamond, NP. Data shown are mean \pm SEM. 
determine differences between the groups. Differences among the means were considered significant when $p<0.05$.

\section{RESULTS}

\section{Mothers}

Dietary intake and weight gain. The animals in the LP group consumed on an average $15 \mathrm{~g}$ of food each day early in pregnancy, and approximately $25 \mathrm{~g} / \mathrm{d}$ after the first week. During the last $3 \mathrm{~d}$ of gestation, the animals in the LP group ate less food. Because the control animals were pair-fed, their food consumption was similar to the LP group (Fig. 1). The calculated protein intake in the LP group was $26 \%$ of the NP group $(\mathrm{LP}, 1.29 \pm 0.1 \mathrm{~g} / \mathrm{d}$; NP, $4.9 \pm 0.4 \mathrm{~g} / \mathrm{d}$ ) (Fig. 1). The weight gain of the LP group animals was comparable to the NP group (Fig. 1). The water intake was significantly lower in the LP group (LP, $22 \pm 5 \mathrm{~mL} / \mathrm{d}$; NP, $35 \pm 10 \mathrm{~mL} / \mathrm{d} ; p<0.01$ ).

Plasma glucose, lactate, and triglycerides. The concentration of glucose, lactate, and triglycerides in the plasma was measured on $\mathrm{d} 21$ of pregnancy. The levels of plasma glucose (LP, $4.8 \pm 2.0$ $\mathrm{mM}$; NP, $6.3 \pm 1.1 \mathrm{mM}$ ), and lactate (LP, $0.9 \pm 0.3 \mathrm{mM}$; NP, $0.7 \pm 0.2 \mathrm{mM}$ ) were not different between the groups. Plasma triglyceride concentration was significantly higher in the LP group $(\mathrm{LP}, 5.0 \pm 2.0 \mathrm{mM}$; NP, $2.5 \pm 0.9 \mathrm{mM} ; p<0.05)$.

Total $\alpha$-amino nitrogen

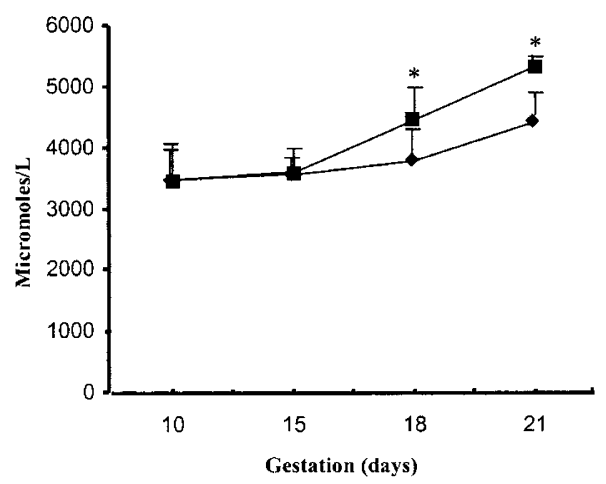

BCAA

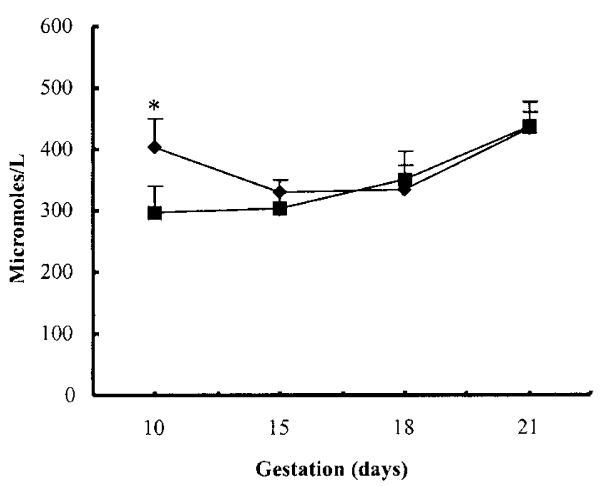

Plasma amino acids and urea. The concentrations of plasma amino acids between d 10 and 21 of gestation are displayed in Figure 2. On d 10 of pregnancy, there was no difference in the plasma level of total $\alpha$-amino nitrogen in the LP and NP groups (LP, $3540 \pm 714 \mu \mathrm{M}$; NP, $3755 \pm 613$ $\mu \mathrm{M})$. However, on $\mathrm{d} 18$ and $\mathrm{d} 21$ of gestation, the LP group showed a significant increase in $\alpha$-amino nitrogen $(p<0.05)$. In contrast, in the NP group, the change in $\alpha$-amino nitrogen in late pregnancy was not significant (Fig. 2). The concentration of nonessential amino acids (NEAA) was not different between the groups on $\mathrm{d} 10$ of gestation. NEAA were significantly higher in the LP group on d 18 and d 21 of pregnancy ( $p<$ 0.05). Specifically, the levels of serine (LP, $372 \pm 69 \mu \mathrm{M}$; $\mathrm{NP}, 213 \pm 79 \mu \mathrm{M} ; p<0.05$ ), glutamine (LP, $750 \pm 116$ $\mu \mathrm{M} ; \mathrm{NP}, 657 \pm 90 \mu \mathrm{M} ; p<0.05)$ and glycine (LP, $348 \pm$ $157 \mu \mathrm{M}$; NP, $194 \pm 43 \mu \mathrm{M} ; p<0.05)$ were significantly higher in the LP group (Fig. 2).

Restriction of dietary protein resulted in significantly lower levels of branch-chain amino acids (BCAA), lysine, and total essential amino acids (EAA) $(p<0.05)$ on $\mathrm{d} 10$ of pregnancy (Fig. 2). The differences in the BCAA and EAA did not persist between the groups in late pregnancy. There was an increase in total EAA in the LP group between d 10 and d $21(\Delta$ EAA: LP $1145 \pm 238 \mu \mathrm{M}, p<0.05)$. The plasma concentration

NEAA

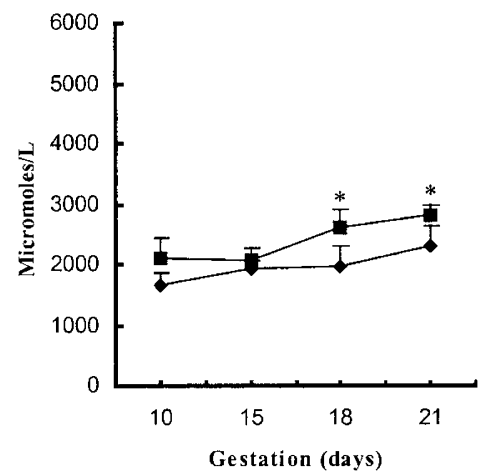

EAA

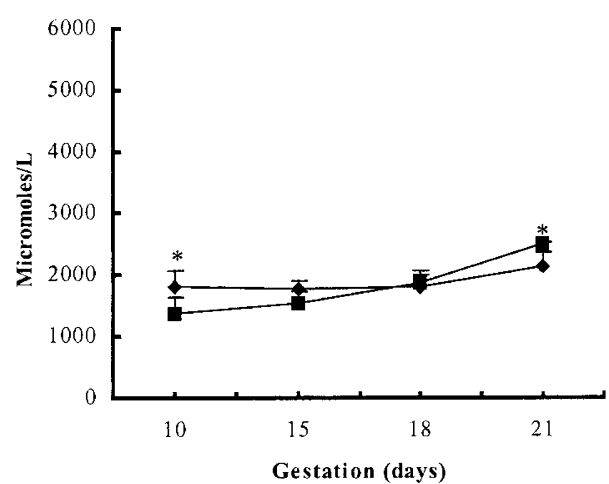

Figure 2. Effect of low-protein diet on concentration of total $\alpha$-amino nitrogen, nonessential amino acids (NEAA), branched chain amino acids (BCAA), and essential amino acids (EAA) during pregnancy. Solid square, LP; solid diamond, NP. Data are mean \pm SEM of five to seven animals in each group. Significantly different in the LP group, ${ }^{*} p<0.05$. 
of lysine was significantly higher in the LP group on $\mathrm{d} 21$ of pregnancy $(\mathrm{LP}, 1367 \pm 171 \mu \mathrm{M} ; \mathrm{NP}, 1068 \pm 298 \mu \mathrm{M}$, $p<0.05)$.

The concentration of plasma urea nitrogen in the NP group was $17.3 \pm 2.1 \mathrm{mg} / \mathrm{dL}$ on $\mathrm{d} 10$ of pregnancy. There was no significant change in plasma urea levels in the NP group with advancing gestation. Protein restriction during pregnancy resulted in a significantly lower plasma concentration of urea between $\mathrm{d} 10$ and $\mathrm{d} 18$ of gestation when compared with NP group $(p<0.01)$. There was a significant increase in plasma urea levels in the LP group $(p<0.01)$ between $\mathrm{d} 18$ and $\mathrm{d} 21$ of pregnancy (Fig. 3).

Oxygen consumption. The rate of oxygen consumption was significantly higher in the LP group $(p<0.01)$ (Fig. 4). It was $\sim 40 \%$ higher on d 18 and d 20 of pregnancy.

Translation initiation factors. Restriction of protein intake during pregnancy did not cause any change in the amount of eIF $2 \alpha \operatorname{Ser}{ }^{51} \mathrm{P}$ and eIF $2 \alpha$ in the maternal liver, so that there was no difference in the ratio of phosphorylated $\operatorname{eIF} 2 \alpha$ and eIF $2 \alpha$ between LP and NP groups (Fig. 5). The levels of eIF4E in the maternal liver were not significantly different in the LP and NP groups. The amount of phosphorylated 4E-BP1 ( $\gamma$-form) in the maternal liver was 4-fold higher in the LP group $(p<0.01)$, when compared with the NP group (Fig. 6). In contrast, the phosphorylated eIF4E in the liver was not different between the groups (Fig. 6). Protein restriction had no impact on the amount of phosphorylated 4E-BP1 and phosphorylated eIF4E in the skeletal muscle of the mother (Fig. 7).

\section{Fetuses}

Protein restriction during pregnancy resulted in intrauterine growth restriction (LP, $4.30 \pm 0.10 \mathrm{~g} ; \mathrm{NP}, 4.80 \pm 0.15 \mathrm{~g} ; p<$ $0.05)$. There was no difference in the litter number between the $\mathrm{LP}(13 \pm 1, n=7)$ and NP $(15 \pm 2, n=7)$ groups. The weight of the placenta was significantly lower in the LP group (LP, $0.40 \pm 0.14 \mathrm{~g} ; \mathrm{NP}, 0.57 \pm 0.02 \mathrm{~g} ; p<0.05)$. In addition, the fetal- placental ratio was higher in the LP group when compared with the NP group (LP, 9.3; NP, 7.0; $p<0.05$ ). The

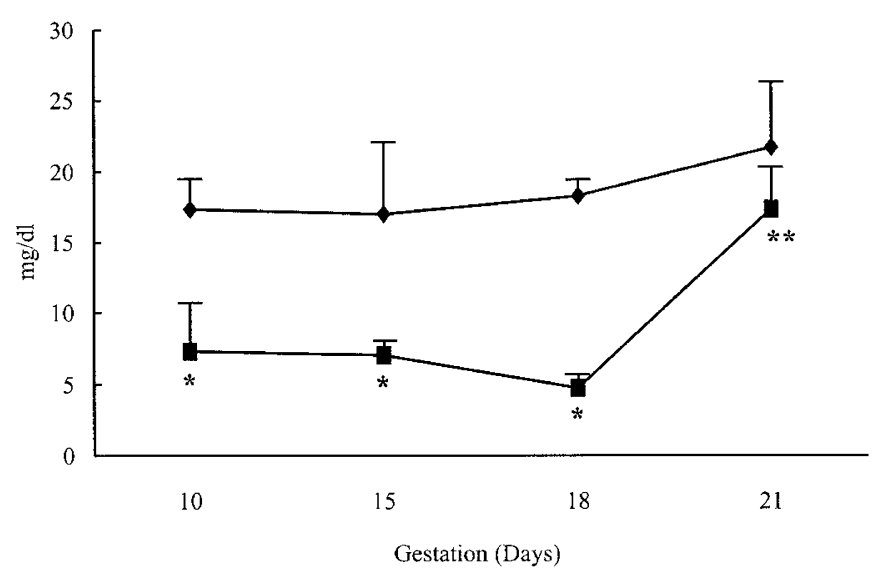

Figure 3. Plasma urea nitrogen concentration during pregnancy. Solid square, LP; solid diamond, NP. Data are mean \pm SEM of seven animals in each group. *Urea nitrogen was significantly lower in the LP group between $\mathrm{d} 10$ and 18 of pregnancy $(p<0.01)$. **Urea nitrogen increased significantly in the LP group between $\mathrm{d} 18$ and 21 of gestation $(p<0.01)$.

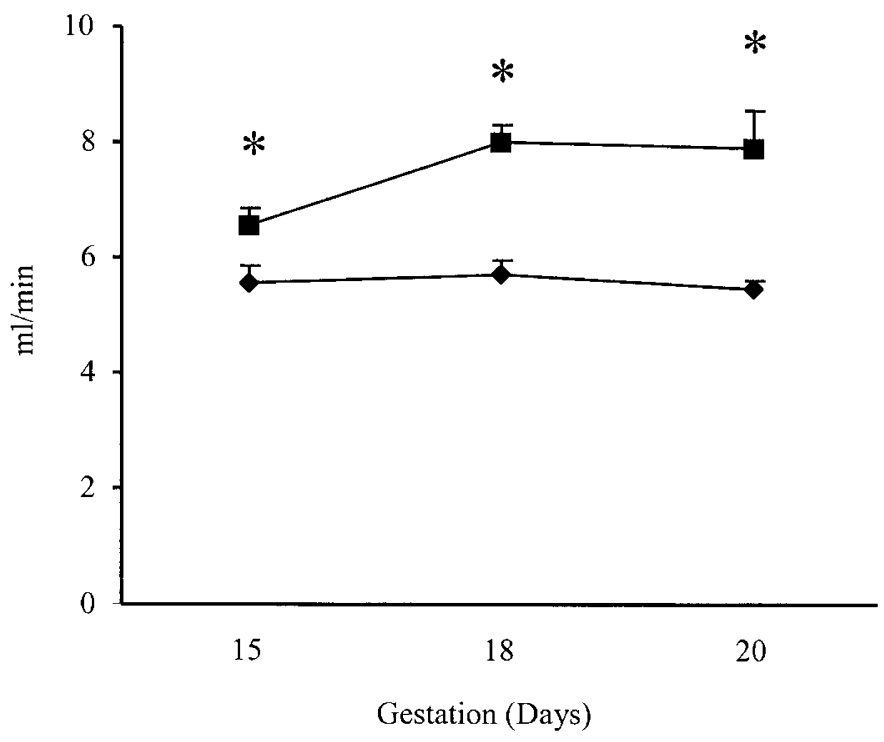

Figure 4. Temporal change in the rate of oxygen consumption in animals placed on the low-protein (LP, $n=5$ ) and normal protein (NP, $n=5$ ) diet during late pregnancy. Solid square, LP; solid diamond, NP. $\dot{\mathrm{V}}_{2}$ was significantly higher in the LP group, $* p<0.01$.

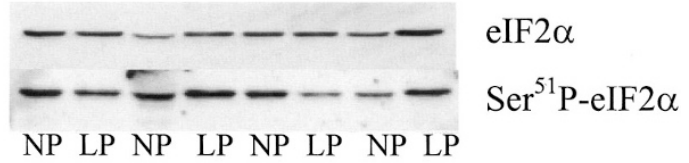

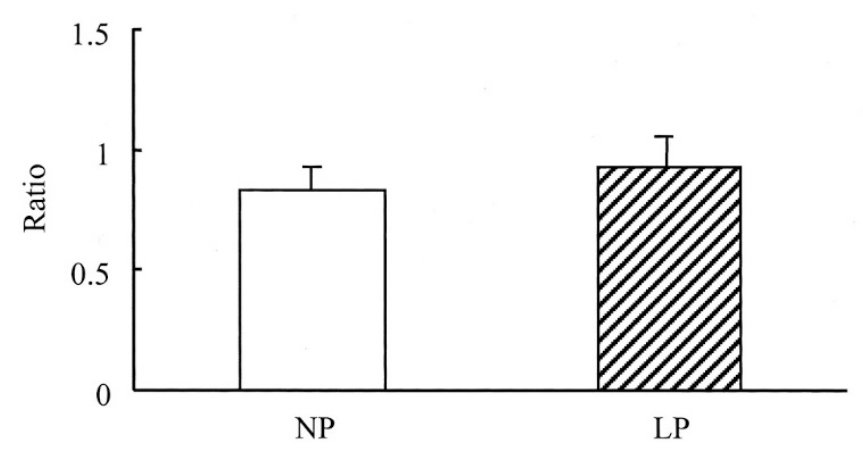

Figure 5. Western blot analysis of protein extracted from the maternal liver on d 21 of pregnancy for eIF $2 \alpha$ and $\operatorname{Ser}^{51}$ phosphorylated eIF $2 \alpha$, as described in "Methods." The blot from four animals in each group is shown in the upper panel, and the ratio of phosphorylated and unphosphorylated eIF $2 \alpha$ presented in the lower panel. Open column, NP; shaded column, LP. No significant difference was observed between the groups.

weight of the liver was significantly lower in the LP fetuses (LP, $0.25 \pm 0.05 \mathrm{~g}$; NP, $0.34 \pm 0.11 \mathrm{~g} ; p<0.05$ ). The weight of the liver relative to body weight was also lower in the IUGR pups (LP, $0.58 \pm 0.05$, NP $0.71 \pm 0.10, p<0.05$ ). The weight of the brain (LP, $188 \pm 14 \mathrm{mg}$; NP, $186 \pm 27 \mathrm{mg}$ ) and heart (LP, $3.3 \pm 0.5 \mathrm{mg}$; NP, $3.2 \pm 0.6 \mathrm{mg}$ ) were not effected by protein restriction during pregnancy. 

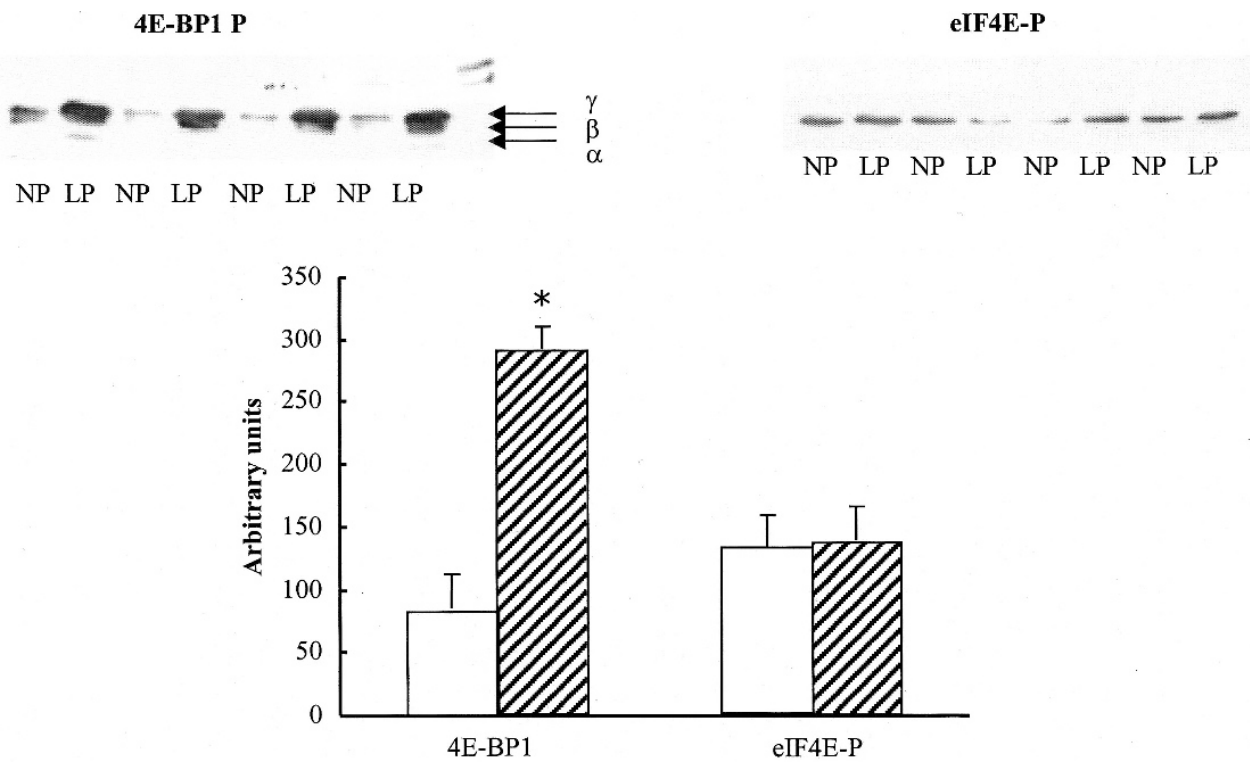

Figure 6. Western blot analysis of protein extracted from the maternal liver on d 21 of pregnancy using antibodies to phosphorylated 4E-BP1 and phosphorylated eIF4E. The data shown are the arbitrary units of the $\gamma$ form of 4E-BP1 as well as the phosphorylated eIF4E. Open column, NP; shaded column, LP. Significantly higher in the LP animals, ${ }^{*} p<0.01$.
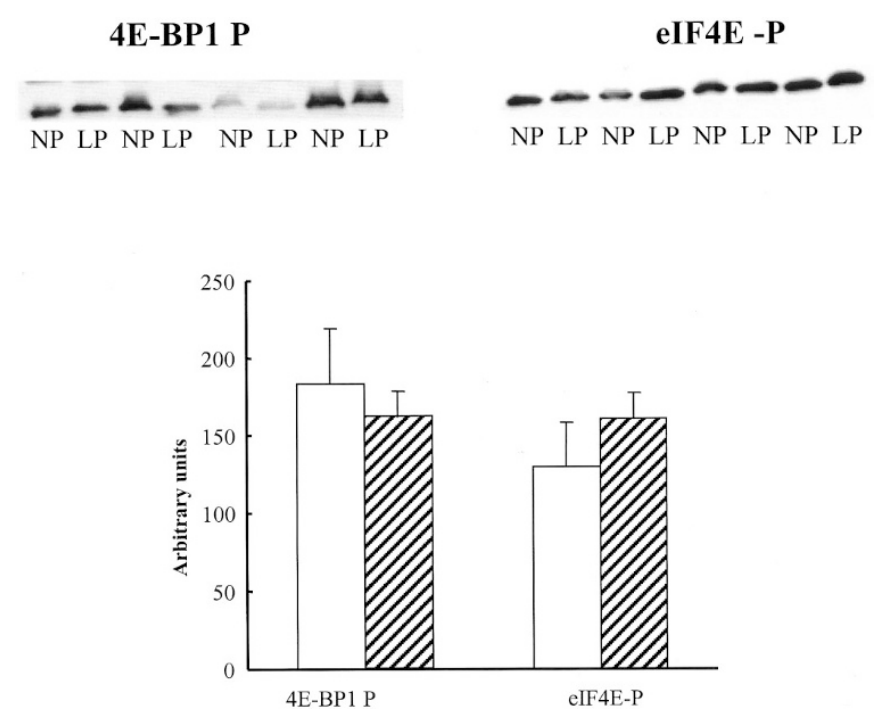

Figure 7. Western blot analysis of protein extracted from the maternal skeletal muscle on $\mathrm{d} 21$ of pregnancy using antibodies phosphorylated 4E-BP1 and phosphorylated eIF-4E. The analysis shown is the $\alpha$-form of 4E-BP1 and phosphorylated eIF4E. Open column, NP; shaded column, LP. No significant differences were observed between the NP and LP groups.

The analysis of the carcass showed no differences in the water (LP, $87 \pm 1 \%$; NP, $87 \pm 1 \%$ ), protein (LP, $6.30 \pm$ $0.90 \%$; NP, $6.57 \pm 1.60 \%$ ), and the fat content (LP, $1.15 \pm$ $0.20 \%$; NP, $1.06 \pm 0.22 \%$ ) between the IUGR and the control group.

The levels of amino acids in the fetal plasma reflected changes in the maternal plasma, i.e. the concentration of serine, glycine, and lysine were higher in the IUGR fetuses $(p<0.05)$. Fetal plasma levels of histidine were significantly lower in the LP group $(p<0.05)$. The concentration of BCAA (leucine, isoleucine, valine) in the fetus was not altered by a low-protein diet. The concentration of total amino nitrogen in the fetal plasma was not different between the groups (Table 2).
Translation initiation factors. In the IUGR pups, there was no change in the levels of eIF $2 \alpha$ in the liver. However, $\mathrm{Ser}^{51}$ phosphorylated eIF $2 \alpha$ was higher in the liver of IUGR pups $(p<0.05)$, resulting in an increase in the ratio of phosphorylated and nonphosphorylated eIF $2 \alpha$. No such change was evident in the fetal skeletal muscle (Fig. 8). The levels of eIF4E, phosphorylated eIF-4E, and phosphorylated 4E-BP1 were not different in the liver and muscle of LP and NP groups (data not shown).

\section{DISCUSSION}

Dietary protein restriction during pregnancy resulted in fetal growth restriction, lower plasma concentration of branched chain amino acid (BCAA) during early gestation, lower levels of plasma urea nitrogen throughout gestation, and a higher rate of oxygen consumption during late gestation. It was associated with higher levels of $\gamma$-form of phosphorylated 4E-BP1 in the maternal liver and higher levels of phosphorylated eIF $2 \alpha$ in the fetal liver. The fetal plasma concentration of histidine was lower in the protein-restricted group.

The adaptive responses to protein restriction during pregnancy should be examined in relation to progression of pregnancy, i.e. early $(0-15 \mathrm{~d})$ before the fetus is growing rapidly, and late (16-22 d), coinciding with the period of rapid growth of the fetus.

Early pregnancy. Although the total plasma alpha amino nitrogen was not different in the NP and LP groups, the levels of essential amino acids and that of BCAA were significantly lower in the LP group. The concentration of amino acids in the plasma is determined by their rate of appearance in and disappearance from plasma. The rate of appearance of an amino acid in plasma is dependent upon dietary protein intake and release from the tissues as a consequence of protein breakdown. The lower levels of essential amino acids and branched chain amino acids in the LP group could be the result of a lower rate of 
Table 2. Concentration of amino acids in the maternal and fetal plasma

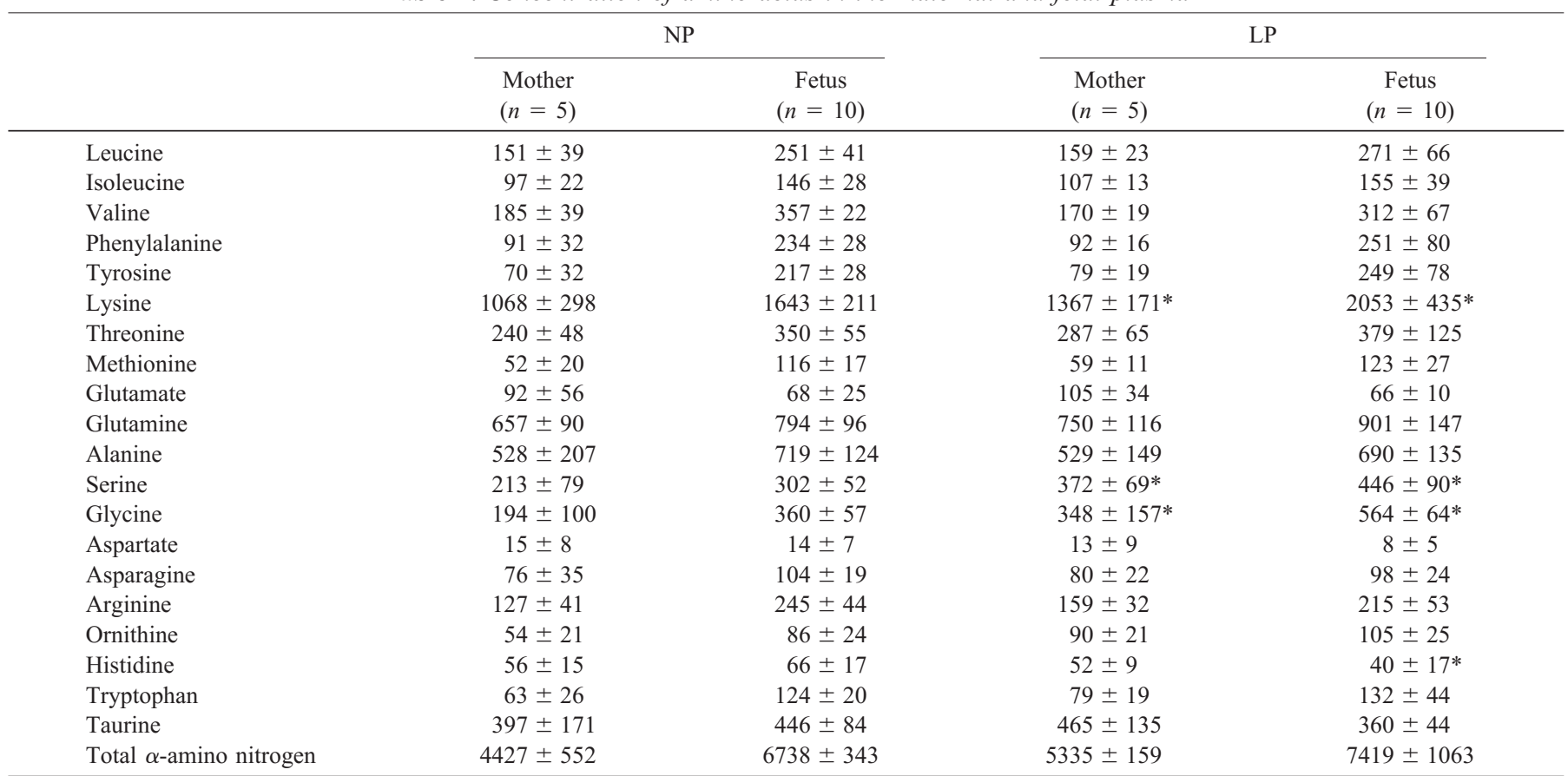

Data shown are in $\mu \mathrm{mol} / \mathrm{L}$; data are mean \pm SEM. Plasma samples of 10 pups from five different litters were analyzed.

$* p<0.01$.

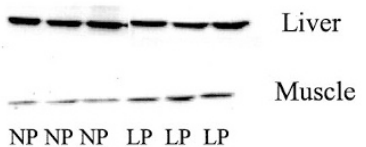

$\mathrm{eIF} 2 \alpha$

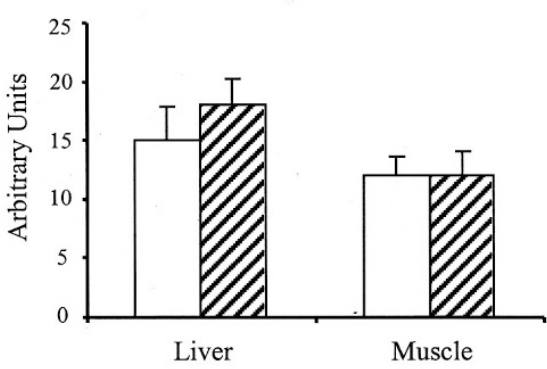

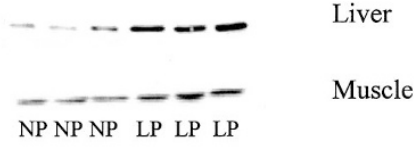

eIF2 $\alpha$ Phosphorylated/total in the fetal tissues

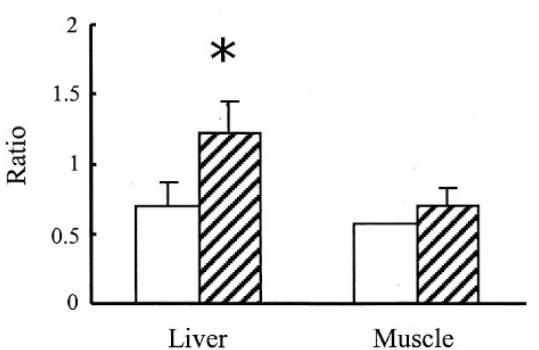

Figure 8. The upper panel shows the representative Western blot of fetal liver and skeletal muscle reacted with antibodies to eIF $2 \alpha$ and Ser ${ }^{51}$ phosphorylated eIF $2 \alpha$ [NP ( $n=10$, from 5 litters); LP $(n=10$, from 5 litters)]. The lower panel displays the total eIF $2 \alpha$ and the ratio of phosphorylated eIF $2 \alpha$ and total eIF $2 \alpha$ in fetal liver and muscle. Open column, NP; shaded column, LP. Significantly higher in the fetal liver, $p<0.05$.

proteolysis during this period of pregnancy. A lower urea nitrogen reflects a lower rate of oxidation of protein. The mechanism of these responses cannot be discerned from the present data. Pregnancy in animals and in humans is associated with a decreased whole-body rate of protein turnover and urea synthesis $(8,9)$. The data in the LP group suggest an exaggeration of these normal responses.

The transfer of amino nitrogen to the fetus is dependent upon the concentration of amino acids in the maternal plasma and the amount of specific amino acid transporter proteins in the placenta $(25,26)$. Therefore, the lower essential amino acid concentration in the maternal compartment could result in decreased transport of amino acids to the fetus if the placental transporters are not up-regulated (27). Data from studies of vesicles isolated from placental trophoblast have shown a decreased or unchanged expression of amino acid transporter protein in response to low-protein diet during pregnancy (11). Thus, the unchanged or decreased amount of transporter protein, combined with lower maternal plasma amino acid concentration, would result in decreased transport of amino acids to the fetus. We speculate that such a decrease in amino acid transport during early pregnancy resulted in growth restriction in the fetus, and effected all tissues by decreasing cell proliferation. The regulatory mechanisms for such an effect need to be explored.

Late pregnancy. As a consequence of rapid growth of the fetal mass, there is an increase in demand for amino acids and 
other substrates during late gestation. As seen in the present study, an increase in fetal demands was associated with an increase in total plasma amino acid concentration, including both essential as well as nonessential amino acids. Although we did not quantify the rate of protein turnover, the increase in plasma amino acid concentration is likely the consequence of increased rate of proteolysis (turnover). The observed increase in oxygen consumption at this stage in pregnancy may be the result of increase in whole-body protein turnover (28). Although the LP diet contained a higher amount of carbohydrates $(76 \%)$, it is unlikely that it contributed to higher energy expenditure. A study in adult humans has shown that isoenergetic diet with higher carbohydrates had no impact on the energy expenditure (29). The observed increase in the energy expenditure in the protein-restricted group in our study is also consistent with published data in nonpregnant rats (13-16). The fetoplacental signals responsible for the change in maternal protein metabolism remain unknown. Such a mediator could influence protein metabolism in the mother, either directly or indirectly via other hormones like insulin or cytokines. Studies in nonpregnant animals and humans placed on low-protein diet show a significant correlation between plasma insulin and IL-6 levels and whole-body protein turnover $(30,31)$.

Apart from higher levels of lysine, serine, and glycine, and lower levels of histidine, the concentration of amino acids in the LP fetuses was not different compared with the NP fetuses. These findings are in contrast to human IUGR, where the concentrations of total $\alpha$-amino nitrogen and essential amino acids were lower (32).

Translation initiation factors. Translation initiation is the critical step in protein synthesis. Changes in the level of translation initiation factors and/or the regulatory protein involved in their phosphorylation can determine the rate of protein synthesis. We observed a 4-fold increase in the phosphorylation of 4E-BP1 in the maternal liver, suggesting an enhanced rate of hepatic protein synthesis in the LP group. Because our data were limited to $\mathrm{d} 21$ of gestation, the precise timing of the increase in relation to advancing gestation cannot be ascertained. These observations are consistent with those of Mayel-Afshar and Grimble (33), who also observed a high fractional rate of hepatic protein synthesis in pregnant rats placed on low-protein diet. Studies in humans placed on lowprotein intake $(0.6 \mathrm{~g} / \mathrm{kg} / \mathrm{d})$ have also demonstrated an increase in synthesis of acute phase proteins (31). These data taken together show that hepatic response to dietary protein restriction consists of an increase in protein synthesis. The increased phosphorylation of 4E-BP1 may have been mediated by specific amino acids, e.g., leucine or by various cytokines or hormones via the mTOR pathway as demonstrated by several investigators $(19,20,34)$.

Phosphorylation of eIF $2 \alpha$ results in sequestration of eIF2B (a guanidine nucleotide exchange factor) and prevents the formation of ternary complex leading to inhibition of the first step in translation initiation (35). We observed that phosphorylated eIF2 $\alpha$ was higher in the liver of the IUGR fetus, indicating inhibition of protein synthesis. We also noted significantly lower levels of plasma histidine in the IUGR pups. The concentration of plasma histidine is inversely related to the activity of histidine decarboxylase, whose activity has been shown to be higher in the IUGR fetus (36). Low histidine levels in the culture medium have been shown also to increase phosphorylation of eIF2 $\alpha$ (18).

In summary, data from the present study show that maternal metabolic responses to dietary protein restriction early in pregnancy are aimed at conserving nitrogen. These adaptive responses result in lower plasma essential amino acid concentration, resulting in decreased delivery of amino nitrogen to the fetus and fetal growth restriction. Late in gestation, there is an increase in maternal plasma amino acid concentration and an increase in energy consumption and protein oxidation. Associated with these responses, there is an increase in hepatic protein synthesis in the mother. Increased levels of phosphorylated eIF $2 \alpha$ in the fetal liver suggest a decreased rate of protein synthesis in IUGR fetuses.

Acknowledgments. The authors thank Jose Mariappuram and Edward Burkett for their assistance with the studies. We also thank Mrs. Joyce Nolan for secretarial help.

\section{REFERENCES}

1. Barker DJ, Eriksson JG, Forsen T, Osmond C 2002 Fetal origins of adult disease strength of effects and biological basis. Int J Epidemiol 31:1235-1239

2. Eriksson J, Forsen T, Tuomilehto J, Osmond C, Barker D 2000 Fetal and childhood growth and hypertension in adult life. Hypertension 36:790-794

3. Forsen T, Eriksson JG, Tuomilehto J, Osmond C, Barker DJ 1999 Growth in utero and during childhood among women who develop coronary heart disease: longitudinal study. BMJ 319:1403-1407

4. Sahajpal V, Ashton N 2003 Renal function and angiotensin AT1 receptor expression in young rats following intrauterine exposure to a maternal low-protein diet. Clin Sci (Lond) 104:607-614

5. Jackson AA, Dunn RL, Marchand MC, Langley-Evans SC 2002 Increased systolic blood pressure in rats induced by a maternal low-protein diet is reversed by dietary supplementation with glycine. Clin Sci (Lond) 103:633-639

6. Bertin E, Gangnerau MN, Bellon G, Bailbe D, Arbelot de Vacqueur A, Protha B 2002 Development of beta-cell mass in fetuses of rats deprived of protein and/or energy in last trimester of pregnancy. Am J Physiol Regul Integr Comp Physiol 283:R623R630

7. Lane RH, Kelley DE, Gruetzmacher EM, Devaskar SU 2001 Uteroplacental insufficiency alters hepatic fatty acid-metabolizing enzymes in juvenile and adult rats. Am J Physiol Regul Integr Comp Physiol 280:R183-R190

8. Kalhan SC 2000 Protein metabolism in pregnancy. Am J Clin Nutr 71:1249S-1255S

9. Kalhan SC 1998 Protein metabolism in pregnancy. In: Cowett RM (ed) Principles of Perinatal-Neonatal Metabolism. Springer-Verlag, New York, pp 207-220

10. Ling PR, Bistrian BR, Blackburn GL, Istfan N 1987 Effect of fetal growth on maternal protein metabolism in postabsorptive rat. Am J Physiol 252:E380-E390

11. Rees WD, Hay SM, Buchan V, Antipatis C, Palmer RM 1999 The effects of maternal protein restriction on the growth of the rat fetus and its amino acid supply. Br J Nutr 81:243-250

12. Langley SC, Jackson AA 1994 Increased systolic blood pressure in adult rats induced by fetal exposure to maternal low protein diets. Clin Sci (Lond) 86:217-222

13. Rothwell NJ, Stock MJ, Tyzbir RS 1983 Mechanisms of thermogenesis induced by low protein diets. Metabolism 32:257-261

14. Kevonian AV, Vander Tuig JG, Romsos DR 1984 Consumption of a low protein diet increases norepinephrine turnover in brown adipose tissue of adult rats. J Nutr 114:543-549

15. Sawaya AL, Lunn PG 1985 Evidence suggesting that the elevated plasma triiodothyronine concentration of rats fed on protein deficient diets is physiologically active. Br J Nutr 53:175-181

16. Swick RW, Gribskov CL 1983 The effect of dietary protein levels on diet-induced thermogenesis in the rat. J Nutr 113:2289-2294

17. Jefferson LS, Kimball SR 2003 Amino acids as regulators of gene expression at the level of mRNA translation. J Nutr 133:2046S-2051S

18. Kimball SR, Horetsky RL, Jefferson LS 1998 Implication of eIF2B rather than eIF4E in the regulation of global protein synthesis by amino acids in L6 myoblasts. J Biol Chem 273:30945-30953

19. Anthony JC, Anthony TG, Kimball SR, Jefferson LS 2001 Signaling pathways involved in translational control of protein synthesis in skeletal muscle by leucine. J Nutr 131:856S-860S

20. Davis TA, Fiorotto ML, Burrin DG, Reeds PJ, Nguyen HV, Beckett PR, Vann RC, O'Connor PM 2002 Stimulation of protein synthesis by both insulin and amino acids is unique to skeletal muscle in neonatal pigs. Am J Physiol Endocrinol Metab 282:E880-E890 
21. Svanberg E, Frost RA, Lang CH, Isgaard J, Jefferson LS, Kimball SR, Vary TC 2000 IGF-I/IGFBP-3 binary complex modulates sepsis-induced inhibition of protein synthesis in skeletal muscle. Am J Physiol Endocrinol Metab 279:E1145-E1158

22. Shah OJ, Anthony JC, Kimball SR, Jefferson LS 2000 4E-BP1 and S6K1: translational integration sites for nutritional and hormonal information in muscle. Am J Physiol Endocrinol Metab 279:E715-E729

23. Turnell DC, Cooper JD 1982 Rapid assay for amino acids in serum or urine by pre-column derivatization and reversed-phase liquid chromatography. Clin Chem 28:527-531

24. Leshner AI, Litwin VA, Squibb RL 1972 A simple method for carcass analysis. Physiol Behav 9:281-282

25. Jansson T 2001 Amino acid transporters in the human placenta. Pediatr Res 49:141147

26. Cramer S, Beveridge M, Kilberg M, Novak D 2002 Physiological importance of system A-mediated amino acid transport to rat fetal development. Am J Physiol Cell Physiol 282:C153-C160

27. Malandro MS, Beveridge MJ, Kilberg MS, Novak DA 1996 Effect of low-protein diet-induced intrauterine growth retardation on rat placental amino acid transport. Am J Physiol 271:C295-C303

28. Welle S, Nair KS 1990 Relationship of resting metabolic rate to body composition and protein turnover. Am J Physiol 258:E990-E998

29. Koursari C, Sidossis LS 2003 Effect of isoenergetic low- and high-carbohydrate diets on substrate kinetics and oxidation in healthy men. Br J Nutr 90:413-418
30. Atinmo T, Baldijao C, Pond WG, Barnes RH 1976 Plasma insulin levels in weaned pigs fed protein or energy restricted diets. J Nutr 106:1654-1658

31. Jackson AA, Phillips G, McClelland I, Jahoor F 2001 Synthesis of hepatic secretory proteins in normal adults consuming a diet marginally adequate in protein. Am J Physiol Gastrointest Liver Physiol 281:G1179-G1187

32. Cetin I, Ronzoni S, Marconi AM, Perugino G, Corbetta C, Battaglia FC, Pardi G 1996 Maternal concentrations and fetal-maternal concentration differences of plasma amino acids in normal and intrauterine growth-restricted pregnancies. Am J Obstet Gynecol 174:1575-1583

33. Mayel-Afshar S, Grimble RF 1983 Changes in protein turnover during gestation in the foetuses, placentas, liver, muscle and whole body of rats given a low-protein diet. Biochim Biophys Acta 756:182-190

34. Kimball SR, Orellana RA, O'Connor PM, Suryawan A, Bush JA, Nguyen HV, Thivierge MC, Jefferson LS, Davis TA 2003 Endotoxin induces differential regulation of mTOR-dependent signaling in skeletal muscle and liver of neonatal pigs. Am J Physiol Endocrinol Metab 285:E637-E644

35. Kimball SR, Fabian JR, Pavitt GD, Hinnebusch AG, Jefferson LS 1998 Regulation of guanine nucleotide exchange through phosphorylation of eukaryotic initiation factor eIF2alpha. Role of the alpha- and delta-subunits of eiF2b. J Biol Chem 273:1284112845

36. Kwong MS, Moore TC, Lemmi CA, Oh W, Thibeault DW 1976 Histidine decarboxylase activity in fetal intrauterine growth-retarded rats. Pediatr Res 10:737-739 